\title{
EDITORIAL
}

\section{In This Issue: Personalizing Health Care}

\author{
Kurt C. Stange, $M D, P b D$, Editor
}

Ann Fam Med 2011;9:194-195. doi:10.1370/afm.1265.

T he articles in this issue inform what both patients and clinicians bring to personalizing health care.

Woolhouse and colleagues ${ }^{1}$ discover that experienced family physicians working in 2 inner cities use a 2 -phase process in caring for women using illicit drugs. The engagement phase attempts to build relationships from a tenuous starting point of patients' difficult past experiences. When successful, the engagement phase leads to a maintenance phase, involving developing continuity and "meeting people where they're at."

Turner et $\mathrm{al}^{2}$ find that, compared with white patients, black patients receive higher rates of care strategies designed to minimize misuse of opioid medications, which has become the largest cause of drugrelated death in many areas. Black patients are more likely to receive urine drug testing, regular office visits, and restricted early refills.

Together, the studies by Woolhouse et al and Turner et al point to the opportunities of bringing together patient-focused and protocol-driven strategies to personalize care.

An examination of the experiences of patients living with heart failure ${ }^{3}$ differentiated treatment burden from illness burden and identified a theory-based framework. The identified domains of treatment burden and the factors that increase this burden provide ripe targets for personalizing care by easing the weight of prescriptions and care organization and increasing the lightness of accessibility, continuity, communication, and care organization.

Can there be a more important time for personalized care than near the end of life? A combined ethics and qualitative analysis by Braun and McCullough identifies 5 pathways by which patients receive life-sustaining treatment by default rather than according to their expressed values and goals. ${ }^{4}$ The findings have implications for personalizing care at a critical moment in life.

In our Annals Journal Club ${ }^{5}$ article, an essay and patient story by de Schweinitz $z^{6}$ shows that in a deepening relationship over time, between both the physician and the patient and the patient and her selfawareness of her past, healing can be fostered in ways that transcend clinical guidelines and algorithms.
Other articles in this issue focus on the other side of the equation of personalizing health care-the training and biomedical evidence that the clinician brings to the relationship.

A clinical trialist ${ }^{7}$ and an editorialist ${ }^{8}$ showcase the effect of case-based lipid-lowering training on an important clinical outcome-reduced 10-year overall and cardiovascular mortality in patients with coronary heart disease.

A study of family physician participation in a new maintenance of certification program now required to some degree by all US certifying medical boards, ${ }^{9}$ and insights from an editorialist from the pediatric board ${ }_{1}^{10}$ show the potential of maintenance of certification to improve health care knowledge and practice. The findings also raise concerns about assuring that these benefits reach physicians and their patients in underserved areas.

Finally, a systematic review provides evidence of treatment effectiveness and trade-offs that can be used to personalize care.

In a meta-analysis of an unintended effect of acid suppression medications, Eom and colleagues ${ }^{11}$ find evidence that long-term use of proton pump inhibitors, but not $\mathrm{H}_{2}$-receptor antagonists, is associated with increased risk of fracture. Editorialists ${ }^{12}$ place these findings into a larger clinical context.

Another article in this issue provides patients and clinicians with useful findings. Brinks et al subject a long-used treatment to its first randomized clinical trial, and find that corticosteroid injections for greater trochanteric pain result in greater reduction of pain at a 3-month follow-up compared with expectant treatment..$^{13}$ These findings, the lack of difference at 1 year, and the limited side effects (a short period of superficial pain at the injection site) can be used to help patients choose their therapy.

Together, the articles in this issue give weight to both sides of the equation of personalized health care. Just as the Chronic Care Mode ${ }^{14}$ is centered on the interactions between an informed, activated patient and a prepared, proactive practice care team, these articles help to load our armamentarium as clinicians and 
health care team members. At the same time, articles in this issue inform efforts to understand, to engage and enable patients, and to develop systems that support the interaction - with the potential for relationship - that is vital for healing ${ }^{15-17}$ and health promotion. ${ }^{18}$

Please join the online discussion of these articles at http://www.AnnFamMed.org.

\section{References}

1. Woolhouse S, Brown JB, Thind A. 'Meeting people where they're at': experiences of family physicians engaging women who use illicit drugs. Ann Fam Med. 2011;9(3):244-249.

2. Becker WC, Starrels JL, Heo M, Li X, Weiner MG, Turner BJ. Racial differences in primary care opioid risk reduction strategies. Ann Fam Med. 2011;9(3):219-225.

3. Gallacher K, May CR, Montori VM, Mair FS. Understanding patients' experiences of treatment burden in chronic heart failure using normalization process theory. Ann Fam Med. 2011;9(3):235-243.

4. Braun UK, McCullough LB. Preventing life-sustaining treatment by default. Ann Fam Med. 2011;9(3):250-256.

5. Stange KC. Symbiosis instead of competing demands: a tale of 2 preventive services. Ann Fam Med. 2011;9(3):iii.

6. de Schweinitz PA. Nasruddin and the coin. Ann Fam Med. 2011; 9(3):268-270.

7. Kiessling $A$, Lewitt $M$, Henriksson P. Case-based training of evidence-based clinical practice in primary care and decreased mortality in patients with coronary heart disease. Ann Fam Med. 2011;9 (3):211-218.
8. Davis D. Can CME save lives? The results of a Swedish, evidencebased continuing education intervention. Ann Fam Med. 2011; 9(3):198-200.

9. Xiearli IM, Rinaldo JCB, Green LA, et al. Family physician participation in maintenance of certification. Ann Fam Med. 2011;9(3): 203-210.

10. Miles PV. Maintenance of certification: the profession's response to physician quality. Ann Fam Med. 2011;9:(3):196-197.

11. Eom C-S, Park SM, Myung S-K, Yun J-M, Ahn J-S. Use of acid suppressive drugs and risk of fracture: a meta-analysis of observational studies. Ann Fam Med. 2011;9(3):257-267.

12. Gill JM, Player MS, Metz DC. Balancing the risks and benefits of proton pump inhibitors. Ann Fam Med. 2011;9:(3):200-202.

13. Brinks A, van Rijn RM, Willemsen SP, et al. Corticosteroid injections for greater trochanteric pain syndrome: a randomized controlled trial in primary care. Ann Fam Med. 2011;9(3):226-234.

14. Improving Chronic Illness Care [Web site]. The Chronic Care Model. http://www.improvingchroniccare.org/index.php?p=The_Chronic_ Care_ModelEs=2. Accessed Mar 27, 2011.

15. Scott JG, Cohen D, DiCicco-Bloom B, Miller WL, Stange KC, Crabtree $\mathrm{BF}$. Understanding healing relationships in primary care. Ann Fam Med. 2008;6(4):315-322.

16. Egnew TR. The meaning of healing: transcending suffering. Ann Fam Med. 2005;3(3):255-262.

17. Egnew TR. Suffering, meaning, and healing: challenges of contemporary medicine. Ann Fam Med. 2009;7(2):170-175.

18. Barr VJ, Robinson S, Marin-Link B, et al. The expanded chronic care model: an integration of concepts and strategies from population health promotion and the chronic care model. Hosp Q. 2003;7(1):73-82. http://www.longwoods.com/content/16763. 